\title{
Studi Kinerja Multipath AODV dengan Menggunakan Network simulator 2 (NS-2)
}

\author{
Bima Bahteradi Putra dan Radityo Anggoro \\ Jurusan Teknik Informatika, Fakultas Teknologi Informasi, Institut Teknologi Sepuluh Nopember (ITS) \\ Jl. Arief Rahman Hakim, Surabaya 60111 Indonesia \\ e-mail: onggo@if.its.ac.id
}

\begin{abstract}
Abstrak-Mobile Ad hoc Network (MANET) merupakan suatu inovasi dalam dunia teknologi yang memungkinkan terjadinya komunikasi jaringan tanpa ketersediaan infrastruktur jaringan yang tetap. Ada beberapa macam protokol routing pada MANET salah satunya adalah AOMDV. AOMDV merupakan pengembangan dari AODV. Perbedaan antara AODV dengan AOMDV adalah jumlah rute yang ditemukan dalam setiap proses pencarian rute. Dalam Tugas Akhir ini, dilakukan penelitian terhadap kinerja AOMDV menggunakan Network simulator 2 (NS-2). Uji coba dilakukan dengan membuat pola traffic koneksi dan pola pergerakan node yang kemudian disimulasikan dengan menggunakan script tcl protocol routing AOMDV. Proses tersebut akan menghasilkan file output berupa trace file. Trace filehasil dari simulasi akan dianalisis untuk menghitung Packet delivery ratio (PDR), Routing Overhead (RO), dan End-to-end Delay. Dari hasil uji coba yang dilakukan, menunjukkan nilai PDR dari AOMDV mengalami penurunan berdasarkan perubahan kecepatan node. Untuk nilai RO dan End-to-end Delay mengalami kenaikan berdasarkan perubahan kecepatan node. Kecepatan node sangat mempengaruhi kinerja AOMDV. Kecepatan node yang tinggi, menyebabkan performa kinerja AOMDV menjadi buruk.
\end{abstract}

\section{Kata Kunci-AODV, AOMDV, MANET, NS-2}

\section{PENDAHULUAN}

$\mathrm{P}$ ERKEMBANGAN teknologi informasi dan komunikasi dewasa ini berkembang dengan pesat. Perkembangan ini ditunjukkan dengan terciptanya berbagai macam teknologi yang membantu meningkatkan produktivitas manusia. Salah satu teknologi yang memudahkan manusia untuk saling berkomunikasi adalah Mobile Ad hoc Network (MANET). MANET memungkinkan terjadinya komunikasi jaringan tanpa bergantung pada ketersedian infrastruktur jaringan yang tetap. Jaringan MANET merupakan jaringan wireless yang terdiri dari kumpulan node-node yang bergerak yang memungkinkan untuk melakukan komunikasi secara langsung.

Dalam teknologi MANET tidak bisa dilepaskan dengan proses pengiriman paket data. Proses pencarian rute untuk mengirimkan data dari sumber ke tujuan disebut dengan routing. Dalam proses routing, data yang berasal dari node sumber dikirimkan ke node-node lain hingga mencapai node tujuan. Terdapat beberapa metode routing pada jaringan MANET salah satunya Ad hoc On-Demand Distance Vector (AODV). Protokol routing AODV bersifat reaktif yang artinya hanya melakukan proses pembentukan rute pada saat dibutuhkan. Setiap kali pencarian rute, AODV hanya menemukan satu pilihan rute atau unipath. Apabila terjadi kegagalan rute, maka AODV akan mengulang proses pencarian rute. Untuk mengatasi hal tersebut, dibutuhkan protokol routing yang memiliki beberapa pilihan rute atau multipath dalam setiap pencarian rute. Oleh karena itu, protokol routing AODV dikembangkan menjadi protokol Ad hoc On-Demand Multipath Distance Vector (AOMDV).

Dalam Tugas Akhir ini, akan dilakukan studi kinerja terhadap protokol routing AOMDV pada topologi jaringan MANET berdasarkan Packet delivery ratio (PDR), Routing Overhead (RO), dan End-to-end Delay.

\section{TINJAUAN PUSTAKA}

\section{A. Mobile Ad hoc Network (MANET)}

Mobile Ad hoc Network (MANET) merupakan sebuah jaringan yang terbentuk dari beberapa node yang bergerak bebas dan dinamis. MANET memungkinkan terjadinya komunikasi jaringan tanpa bergantung pada ketersedian infrastruktur jaringan yang tetap. Setiap node dalam jaringan MANET dapat bertindak sebagai host dan router. Setiap node dapat saling melakukan komunikasi antara yang satu dengan yang lainnya tanpa adanya access point.

Perangkat di jaringan MANET harus mampu mendeteksi keberadaan perangkat lain dan melakukan pengaturan yang diperlukan untuk melakukan komunikasi dan berbagi data. Pada MANET memungkinkan perangkat untuk mempertahankan koneksi ke jaringan serta dengan mudah menambahkan dan menghapus perangkat pada jaringan. Karena pergerakan node yang dinamis, topologi jaringan dapat berubah dengan cepat dan tak terduga dari waktu ke waktu. Jaringan MANET bersifat desentralisasi, di mana organisasi jaringan dan pengiriman pesan harus dijalankan oleh node sendiri [1].

MANET memiliki beberapa karakteristik yaitu:

1. Topologi yang dinamis: Node pada MANET dapat bergerak secara bebas dan berpindah-pindah kemana saja. Topologi jaringan yang bisanya multihop dapat berubah secara acak dan tidak terpola.

2. Keterbatasan bandwidth: Link pada jaringan nirkabel memiliki kapasitas rendah daripada jaringan kabel. Selain itu, throughput komunikasi nirkabel seringkali lebih rendah dari tingkat transmisi maksimum radio. Hal ini dapat 
menyebabkan terjadinya congestion (kemacetan).

3. Keterbatasan energi: Karena bersifat mobile, semua node pada MANET dapat dipastikan sangat mengandalkan baterai sebagai sumber energi. Sehingga diperlukan desain sistem untuk optimasi energi.

4. Keterbatasan Keamanan: Jaringan nirkabel pada umumnya sangat rentan terhadap ancaman keamanan. Beberapa ancaman seperti eavesdroping, spoofing dan denial of service harus lebih diperhatikan dengan cermat [2].

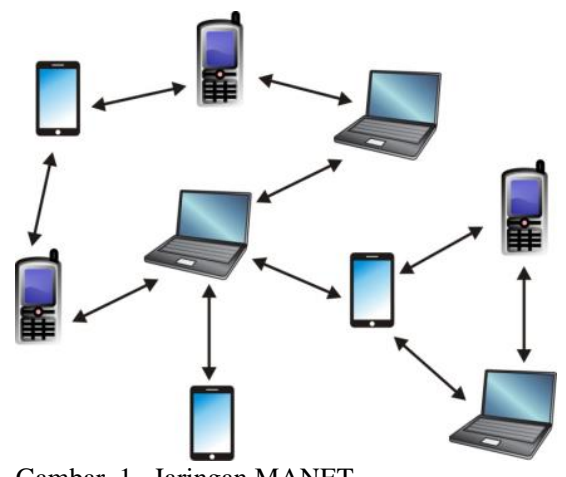

Gambar. 1. Jaringan MANET

\section{B. Ad Hoc On-Demand Multipath Distance Vector (AOMDV)}

Protokol routing Ad Hoc On-Demand Multipath Distance Vector (AOMDV) [3] memiliki banyak persamaan karakteristik dengan Protokol routing AODV. AOMDV memiliki konsep berbasis vektor dan menggunakan pendekatan hop by hop. AOMDV juga memiliki dua fitur utama yang mirip dengan AODV yaitu route discovery dan route maintenance. Perbedaan utama antara AODV dan AOMDV adalah jumlah rute yang ditemukan di setiap pencarian rute atau route discovery.

\section{B.1. Route Discovery}

Ketika source node memerlukan rute untuk melakukan komunikasi dengan destination node, maka source node akan mengirimkan paket route request (RREQ) secara broadcast ke node-node tetangga di dalam jaringan dan menunggu route reply (RREP). Berbeda dengan AODV, AOMDV menerima semua salinan paket RREQ untuk membuat reverse path.

Ketika intermediate node menerima paket RREQ, node ini akan mengecek apakah ada satu atau lebih forward path ke destination yang valid. Jika ada, node ini akan membuat paket RREP dan mengirim kembali ke source node melalui reverse path. Jika tidak ada, maka intermediate node akan meneruskan paket RREQ hingga ke destination node, kemudian destination node akan membalas dengan paket RREP.

Proses route discovery pada AOMDV ditunjukkan Pada Gambar 2. Ketika node S (source node) hendak melakukan komunikasi terhadap node D (destination node), pertama kali node $\mathrm{S}$ mengirimkan paket RREQ secara broadcast ke nodenode tetangganya yaitu ke node $\mathrm{H}$ dan node $\mathrm{J}$. Apabila nodenode tersebut dalam hal ini node $\mathrm{H}$ dan node $\mathrm{J}$ bukan merupakan destination node, maka node tersebut akan meneruskan paket RREQ secara broadcast ke node tetangganya tetapi tidak ke source node. Selain itu, node $\mathrm{H}$ dan node $\mathrm{J}$ akan melakukan set up reverse path. Proses tersebut berulang hingga paket RREQ tersebut diterima oleh destination node yatiu node $\mathrm{D}$. Selanjutnya, node $\mathrm{D}$ akan mengiirmkan paket RREP sebagai balasan dari paket RREQ yang diterimanya. Node-node penerima paket RREP akan melakukan set-up forward path.

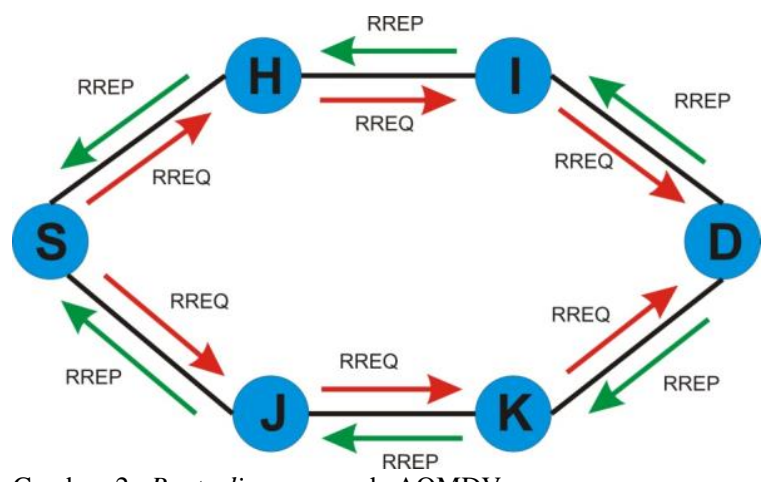

Gambar. 2. Route discovery pada AOMDV

Pada AODV, apabila destination node menerima paket RREQ ganda, maka paket RREQ yang terakhir diterima destination node akan di-drop. Berbeda dengan AODV, AOMDV menerima semua salian paket RREQ dan akan digunakan untuk membentuk rute cadangan dari source node ke destination node. Dengan demikian, AOMDV akan memiliki lebih dari satu path (multipath) sehingga apabila terjadi kerusakan rute atau rute pengiriman putus saat proses pengiriman, source node tidak perlu lagi melakukan proses route discovery seperti pada AODV karena source node akan menggunakan rute cadangan yang telah dibentuk saat route discovery.

\section{B.2. Route Maintenance}

Route maintenance pada AOMDV adalah pengembangan sederhana yang ada pada route maintenance AODV. AOMDV juga menggunakan peket route error (RERR) untuk mengirimkan pesan error. Sebuah node akan mengirimkan paket RERR apabaila path ke destination node rusak. AOMDV memiliki beberapa rute untuk menjaga agar komunikasi tetap berlangsung yaitu ketika sebuah node menemui link yang rusak maka node tersebut segera memilih rute cadangan.

Proses pengiriman paket RRER pada AOMDV ditunjukkan pada Gambar 3. Pada saat terjadi kerusakan link yang menghubungkan antara node I dengan node $\mathrm{D}$, maka node I akan mengirimkan paket RRER ke node $\mathrm{H}$. Seterusnya, node $\mathrm{H}$ akan mengirimkan paket RRER ke node $\mathrm{S}$. Setelah node $\mathrm{S}$ menerima paket RRER, proses komunikasi akan dilakukan kembali dengan menggunakan rute cadangan apabila masih tersedia. Apabila tidak tersedia rute cadangan, maka node $\mathrm{S}$ akan melakukan proses route discovery.

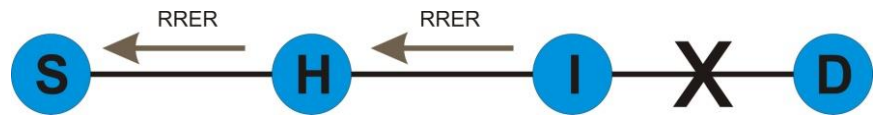

Gambar. 3. Route maintenance pada AOMDV 


\section{PERANCANGAN}

\section{A. Deskripsi Umum}

Pada Tugas Akhir ini akan dilakukan analisis kinerja terhadap protokol routing AOMDV pada jaringan MANET. Ilustrasi rancangan simulasi dapat dilihat pada Gambar 4.

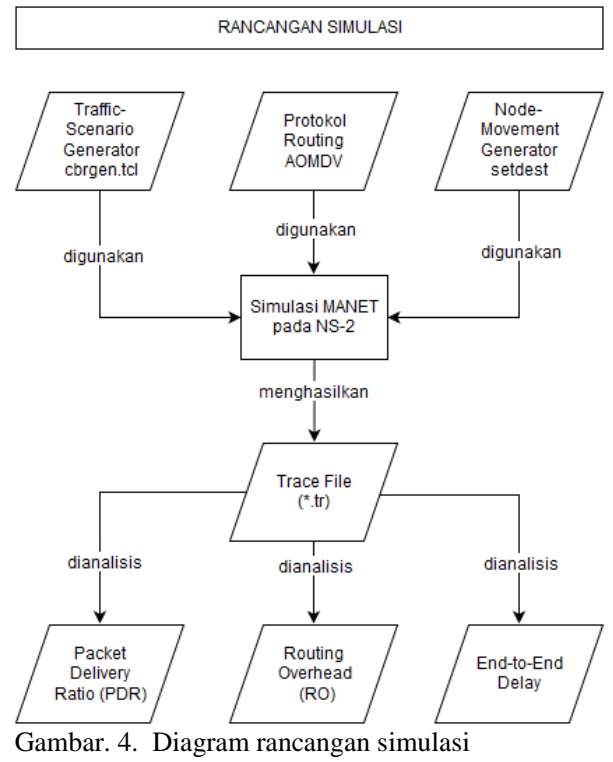

Dalam pengujian ini, digunakan 50 node untuk simulasi protokol routing AOMDV. Untuk kecepatan maksimal pergerakan node dibuat bervariasi yaitu $5 \mathrm{~m} / \mathrm{s}, 10 \mathrm{~m} / \mathrm{s}$, dan 15 $\mathrm{m} / \mathrm{s}$. Hasil dari proses uji coba ini yaitu berupa trace fileyang nantinya akan digunakan untuk menghitung Packet delivery ratio (PDR), Routing Overhead (RO) dan End-to-end Delay.

\section{B. Perancangan Skenario}

Perancangan skenario uji coba mobilitas diawali dengan membuat pola traffic koneksi antara node secara acak menggunakan Traffic-Scenario Generator. Kemudian membuat pola pergerakan node-node secara acak menggunakan Node-Movement Generator. Pada Tugas Akhir ini, pergerakan node-node menggunakan 3 variasi kecepatan maksimal yaitu $5 \mathrm{~m} / \mathrm{s}, 10 \mathrm{~m} / \mathrm{s}$, dan $15 \mathrm{~m} / \mathrm{s}$.

\section{B.1. Menentukan Pola Traffic Koneksi}

Pola Traffic koneksi dibuat dengan menjalankan script cbgren.tcl yang nantinya akan menghasilkan output berupa file. File tersebut digunakan untuk mengatur pola traffic koneksi secara acak antara node dalam simulasi. Parameter yang digunakan untuk membuat pola traffic koneksi dapat dilihat pada Tabel 1 .

\section{B.2. Menentukan Pola Pergerakan Node}

Pola Pergerakan Node dibuat dengan menggunkan NodeMovement Generator yang nantinya akan menghasilkan output berupa file. Filetersebut digunakan untuk mengatur node-node agar dapat bergerak secara acak dalam simulasi. Parameter yang digunakan untuk membuat pola pergerakan node dapat dilihat pada Tabel 2.
Tabel 1.

Parameter pola traffic koneksi

\begin{tabular}{clc}
\hline \hline No. & \multicolumn{1}{c}{ Parameter } & Spesifikasi \\
\hline 1 & Jenis traffic (-type) & CBR \\
2 & Jumlah node $(-\mathrm{nn})$ & 50 \\
3 & Jumlah seed $(-\mathrm{s})$ & 1 \\
4 & Jumlah koneksi (-mc) & 1 \\
5 & Jumlah paket per detik (-rate) & 1 \\
\hline \hline
\end{tabular}

Tabel 2.

Parameter pola pergerakan node

\begin{tabular}{clc}
\hline \hline No. & \multicolumn{1}{c}{ Parameter } & Spesifikasi \\
\hline 1 & Jumlah node $(-\mathrm{n})$ & 20 \\
2 & Waktu jeda (-p) & $2 \mathrm{~s}$ \\
3 & Kecepatan maksimal node $(-\mathrm{M})$ & $-5 \mathrm{~m} / \mathrm{s}$ \\
& & $-10 \mathrm{~m} / \mathrm{s}$ \\
& & $-15 \mathrm{~m} / \mathrm{s}$ \\
4 & Waktu simulasi (-t) & $500 \mathrm{~s}$ \\
5 & Panjang maksimal area simulasi (-x) & $800 \mathrm{~m}$ \\
6 & Lebar maksimal area simulasi (-y) & $800 \mathrm{~m}$ \\
\hline \hline
\end{tabular}

\section{Perancangan Simulasi pada NS-2}

Pada perancangan kode NS-2 dengan konfigurasi MANET, dilakukan penggabungan skenario pola traffic koneksi dan pola pergerakan node dengan skrip TCL yang diberikan parameterparameter untuk membangun percobaan simulasi MANET pada NS-2. Berikut parameter simulasi perancangan sistem MANET yang dapat digunakan dapat dilihat pada Tabel 3.

Tabel 3.

Parameter simulasi

\begin{tabular}{cll}
\hline \hline No. & \multicolumn{1}{c}{ Parameter } & \multicolumn{1}{c}{ Spesifikasi } \\
\hline 1 & Network simulator & NS-2 versi 2.35 \\
2 & Protokol routing & AOMDV \\
3 & Waktu simulasi & $500 \mathrm{~s}$ \\
4 & Area simulasi & $800 \mathrm{~m} \mathrm{x} 800 \mathrm{~m}$ \\
5 & Jumlah node & 50 \\
6 & Radius transmisi & $100 \mathrm{~m}$ \\
7 & Source / destination & Statik (node 1/node 2) \\
8 & Protokol MAC & IEEE 802.11 \\
9 & Model propagasi & Two-ray ground \\
& & propagation model \\
10 & Tipe antena & OmniAntenna \\
11 & Tipe Interface Queue & Droptail/PriQueue \\
12 & Mobility model & Random Waypoint \\
13 & Tipe kanal & Wireless channel \\
14 & Tipe trace & Old Wireless Format \\
& & Trace \\
\hline \hline
\end{tabular}

\section{Perancangan Metrik Analisis}

Metrik yang akan dianalisis pada Tugas Akhir ini adalah Packet delivery ratio (PDR), Routing Overhead (RO), dan End-to-end Delay. Penjelasannya sebagai berikut:

\section{D.1. Packet delivery ratio (PDR)}

PDR dihitung dari perbandingan antara paket yang dikirim dengan paket yang diterima. PDR dihitung dengan menggunakan (1), dimana received adalah banyaknya paket data yang diterima dan sent adalah banyaknya paket data yang dikirimkan.

$P D R=\frac{\sum \text { received }}{\sum \text { sent }} \times 100$ 


\section{D.2. Routing Overhead (RO)}

Routing Overhead (RO) adalah jumlah paket kontrol routing yang ditransimisikan per data paket yang terkirim ke tujuan selama simulasi terjadi. RO dihitung berdasarkan paket routing yang ditransmisikan. Baris yang mengandung RO pada trace fileditandai dengan paket yang bertipe send (s) / forward (f) dan terdapat header paket dari protokol AOMDV.

\section{D.3. End-to-end Delay}

End-to-end Delay dihitung dari rata-rata delay antara waktu paket diterima dan waktu paket dikirim. End-to-end Delay dihitung dengan menggunakan (2), dimana $t_{\text {received[i] }}$ adalah waktu penerimaan paket dengan urutan / id ke-i, $\mathrm{t}_{\text {sent[i] }}$ adalah waktu pengiriman paket dengan urutan / id ke-i, dan sent adalah banyaknya paket data yang dikirimkan.

End to End Delay $=\frac{\sum_{\text {issent }}^{i=0} t_{\text {Teceived [i] }}-t_{\text {sent[i] }}}{\text { sent }}$

\section{PENGUJIAN DAN EVALUASI}

\section{A. Analisis Packet delivery ratio (PDR)}

Gambar 5 menunjukkan grafik performa PDR AOMDV pada jaringan MANET. Terlihat bahwa PDR yang dihasilkan semakin menurun dengan bertambahnya kecepatan maksimal node. Ketika kecepatan maksimal node $5 \mathrm{~m} / \mathrm{s}$, PDR yang dihasilkan yaitu $30,53 \%$. Perubahan nilai PDR terjadi ketika kecepatan maksimal node dinaikkan menjadi $10 \mathrm{~m} / \mathrm{s}$. Nilai PDR menurun menjadi $16,01 \%$. Begitu juga pada saat kecepatan node dinaikkan lagi menjadi $15 \mathrm{~m} / \mathrm{s}$. Nilai PDR semakin menurun menjadi $10,59 \%$.

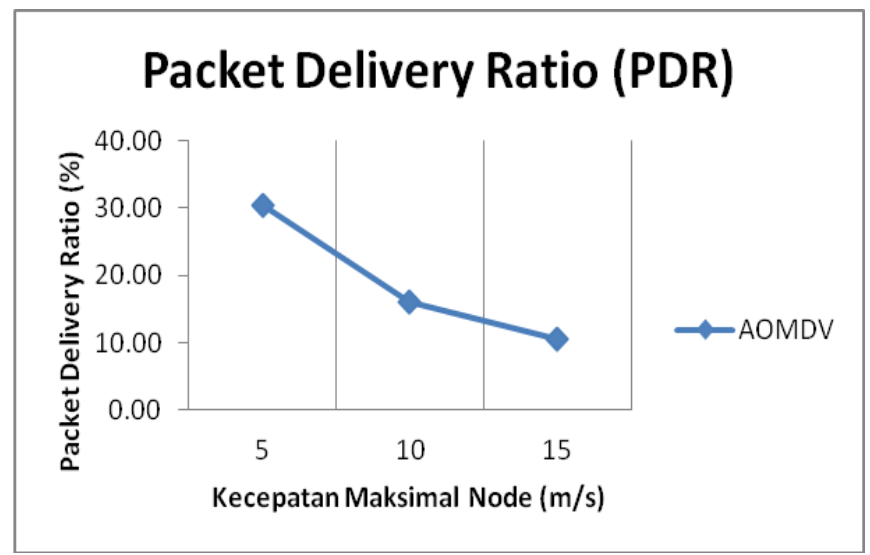

Gambar. 5. Grafik Packet delivery ratio (PDR) AOMDV

Pada jaringan MANET, node-node bergerak sangat dinamis. Semakin cepat pergerakan node, kemungkinan terjadinya banyak rute yang putus saat pengiriman data ataupun kegagalan routing yang dilakukan oleh AOMDV semakin besar, sehingga menyebabkan paket data yang dikirim tidak sampai ke tujuan. Hal ini telah dibuktikan dengan nilai PDR yang dihasilkan semakin menurun dengan bertambahnya kecepatan maksimal node.

\section{B. Analisis Routing Overhead (RO)}

Gambar 6 menunjukkan grafik hasil pengujian Routing Overhead (RO) pada AOMDV. Nilai RO menunjukkan peningkatan berdasarkan kecepatan maksimal node dalam simulasi. Pada saat kecepatan node $5 \mathrm{~m} / \mathrm{s}$, nilai RO yang dihasilkan yaitu 3566,2. Namun pada saat kecepatan maksimal node dinaikkan menjadi $10 \mathrm{~m} / \mathrm{s}$ terlihat bahwa nilai RO mengalami peningkatan menjadi 4125,5. Peningkatan nilai RO juga terjadi ketika kecepatan maksimal node dinaikkan menjadi $15 \mathrm{~m} / \mathrm{s}$. Pada saat kecepatan maksimal node $15 \mathrm{~m} / \mathrm{s}$, nilai RO naik menjadi 4654,3.

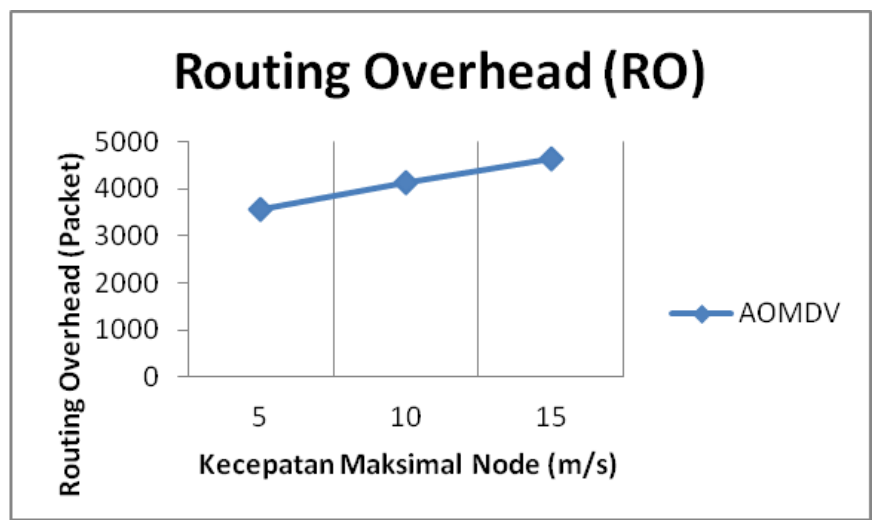

Gambar. 6. Grafik Routing Overhead (RO) AOMDV

Kenaikan kecepatan maksimal node mengakibatkan kenaikan pada nilai RO. Hal ini terjadi karena ketika node bergerak cepat, pengiriman paket routing berjenis send maupun forward yang dihasilkan lebih banyak. Dengan semakin banyaknya paket routing send dan forward yang dihasilkan, pengiriman paket data yang dilakukan memiliki kemungkinan yang lebih besar untuk sampai ke node tujuan.

\section{Analisis End-to-end Delay}

Performa End-to-end Delay pada AOMDV menunjukkan peningkatan berdasarkan kecepatan maksimal node dalam simulasi seperti yang ditunjukkan pada pada Gambar 7. Nilai end-to-end delay menunjukkan 0,24 second pada saat kecepatan node $5 \mathrm{~m} / \mathrm{s}$. Ketika kecepatan node dinaikkan menjadi $10 \mathrm{~m} / \mathrm{s}$, terlihat bahwa nilai end-to-end delay mengalami peningkatan menjadi 0,32 second. Peningkatan nilai end-to-end delay juga terlihat ketika kecepatan node dinaikkan menjadi $15 \mathrm{~m} / \mathrm{s}$ yaitu 0,89 second.

Peningkatan nilai end-to-end delay disebabkan karena pergerakan node yang cepat dan dinamis. Pergerakan node yang cepat bisa mengakibatkan node bergerak menjauh dari jangkauan transmission range. Hal ini memungkinkan terjadinya rute putus saat pengiriman paket data sehingga pengiriman paket dimasukkan ke dalam antrian dan menunggu rute baru terbetuk sebelum pengiriman paket data dilanjutkan kembali. 


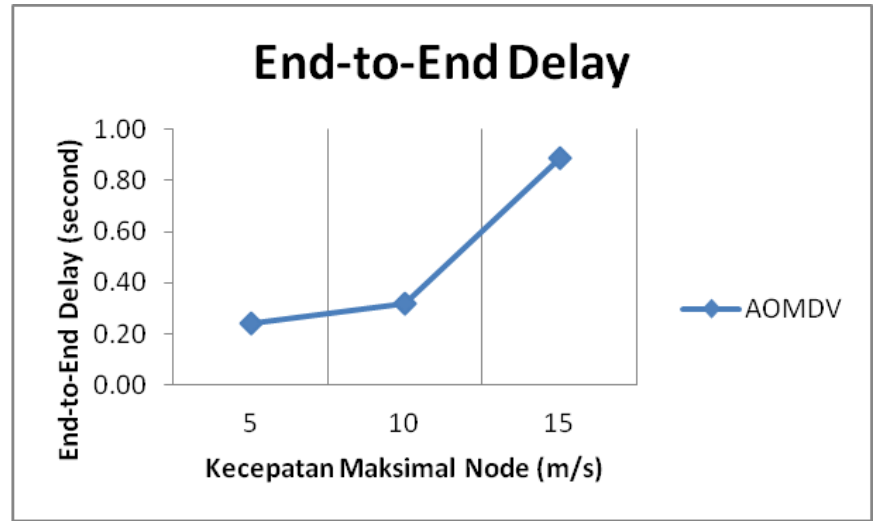

Gambar. 7. Grafik End-to-end Delay AOMDV

\section{KESIMPULAN}

Kesimpulan yang dapat diambil dalam Tugas Akhir ini adalah sebagai berikut:

1) Performa kinerja protokol routing AOMDV pada jaringan MANET adalah sebagai berikut:

- Dengan penambahan jumlah kecepatan node, performa Packet delivery ratio yang dihasilkan mengalami penurunan. Penurunan sebesar $14.5 \%$ dari kecepatan maksimal node $5 \mathrm{~m} / \mathrm{s}$ ke $10 \mathrm{~m} / \mathrm{s}$ dan penurunan sebesar $5.42 \%$ dari kecepatan maksimal node $10 \mathrm{~m} / \mathrm{s}$ ke $15 \mathrm{~m} / \mathrm{s}$.

- Routing Overhead yang dihasilkan mengalami peningkatan berdasarkan penambahan jumlah kecepatan node dengan kenaikan rata-rata 544.05.

- Performa End-to-end Delay yang dihasilkan juga mengalami peningkatan berdasarkan penambahan jumlah kecepatan node. Kenaikan sebesar 0.08 s dari kecepatan maksimal node $5 \mathrm{~m} / \mathrm{s}$ ke $10 \mathrm{~m} / \mathrm{s}$ dan kenaikan sebesar $0.57 \mathrm{~s}$ dari kecepatan maksimal node $10 \mathrm{~m} / \mathrm{s}$ ke $15 \mathrm{~m} / \mathrm{s}$.

2) Kecepatan node sangat mempengaruhi performa kinerja protokol routing AOMDV. Node yang bergerak dengan cepat menyebabkan perubahan topologi jaringan dengan cepat dan tak terduga dari waktu ke waktu sehingga performa kinerja AOMDV menjadi buruk.

\section{UCAPAN TERIMA KASIH}

Penulis B.B.P. mengucapkan puji syukur kepada Allah SWT yang melimpahkan rahmat dan karunia-Nya sehingga penulis dapat menyelesaikan penelitian ini dengan lancar. Penulis juga mengucapkan terima kasih kepada Bapak Radityo Anggoro yang telah membantu penulis dalam menyelesaikan penelitian ini. Penulis juga mengucapkan terima kasih kepada pihak-pihak lain yang turut membantu kelancaran penelitian ini.

\section{DAFTAR PUSTAKA}

[1] A. O. Bang and P. L. Ramteke, "MANET : History, Challenges And Applications," International Journal of Application or Innovation in Engineering \& Management, vol. II, no. 9, 2013.

[2] S. Corson and J. Macker, "Mobile Ad hoc Networking (MANET) : Routing Protocol Performance Issues and Evaluation Considerations," Network Working Group, 1999.

[3] M. K. Marina and S. R. Das, "Ad hoc on-demand multipath distance vector routing," WIRELESS COMMUNICATIONS AND MOBILE COMPUTING, 2006. 